\title{
Correction to: Providence nighttime bracing is effective in treatment for adolescent idiopathic scoliosis even in curves larger than $35^{\circ}$
}

\author{
Ane Simony ${ }^{1} \cdot$ Inge Beuschau $^{1} \cdot$ Lena Quisth $^{1} \cdot$ Stig Mindedahl Jespersen $^{1} \cdot$ Leah Yaccat Carreon ${ }^{1}$. \\ Mikkel Osterheden Andersen ${ }^{1}$
}

Published online: 6 November 2019

๑) Springer-Verlag GmbH Germany, part of Springer Nature 2019

\section{Correction To: European Spine Journal (2019) 28:2020-2024 \\ https://doi.org/10.1007/s00586-019-06077-z}

SpineTech should correctly been written as Spinal Technology, Inc.

The Providence Nocturnal Scoliosis ${ }^{\circledR}$ System is a registered trademark of Spinal Technology, Inc.

Publisher's Note Springer Nature remains neutral with regard to jurisdictional claims in published maps and institutional affiliations.

The original article can be found online at https://doi.org/10.1007/ s00586-019-06077-z.

Ane Simony

ane.simony1@ rsyd.dk

1 Sector for Spine Surgery and Research, Middelfart Hospital, Ostre Hougvej 55, 5500 Middelfart, Denmark 